\title{
Effect of Different Levels of I.B.A Concentration on Clonal Propagation of Eucalyptus Species in Ghana West Africa.
}

Nana Yaw Sarpong (D nsarpy09@gmail.com )

Kwame Nkrumah University of Science and Technology https://orcid.org/0000-0001-7099-2138

Frank Ofori Agyemang

Kwame Nkrumah University of Science and Technology

Daniel E.K.A Siaw

Kwame Nkrumah University of Science and Technology

\section{Essakku Menason}

Miro Forestry Ghana Limited

\section{Research}

Keywords: Clone, auxin, adventitious rooting, hybrid, cutting, ortet

Posted Date: December 15th, 2020

DOI: https://doi.org/10.21203/rs.3.rs-126050/v1

License: (9) This work is licensed under a Creative Commons Attribution 4.0 International License. Read Full License

Version of Record: A version of this preprint was published at Tropical Agroecosystems on November 13th, 2020. See the published version at https://doi.org/10.26480/taec.01.2021.26.29. 


\section{Abstract}

\section{Background}

Increasing global wood demands have necessitated an overall push for cost-effective methods of vegetative propagation using cuttings. Vegetative plant propagation through cuttings although a breakthrough is mostly hampered with the inability of cuttings to root effectively to achieve maximum yield. Ten clones each of Eucalyptus grandis $x$ Eucalyptus urophylla (E. grandis $x$ E. urophylla) and Eucalyptus pellita (E. pellita) were treated with Indole-3-butyric acid (IBA) concentrations of $0 \mathrm{ppm}$ (control), 2000 ppm, 3000 ppm and 4000 ppm respectively.

\section{Results}

Overall mean survival of cuttings was low $(<50 \%)$ for all concentrations of IBA used in this research. Survival rates of individual clones however varied from clone to clone. E. grandis $x$ E. urophylla cuttings had the highest mean survival (43.39\%) when treated with 2000 ppm of IBA and lowest mean survival $(37.86 \%)$ when treated with $0 \mathrm{ppm}$. Results from the survival rates of $E$. grandis $\times E$. Urophylla and Eucalyptus pellita cuttings were subjected to an Analysis of Variance test to identify any significant differences between hormone concentration and cutting survival. ANOVA results indicated that differences between cutting-IBA concentrations for $E$. grandis $\times$ E. Urophylla were significant $\left(\mathrm{p}=1.85 \times 10^{-}\right.$ $\left.{ }^{08}\right)$ which is lower than standard $p$ value $(p=0.05)$ used in the test.

For E. pellita (P) cuttings the highest mean survival (27.14\%) was achieved when treated with $2000 \mathrm{ppm}$ of Indole-3-butyric acid (IBA). Individual clones however showed significant differences in survival. $E$. pellita clone P2 achieved the highest survival (52.68\%) in the control experiment (0 ppm). Some clones i.e P51 and P82 achieved survivals of less than $10 \%$ in all four levels of IBA

\section{Conclusion}

The best surviving Eucalyptus grandis $x$ Eucalyptus urophylla clone (GH11) achieved a mean survival rate of $75 \%$ when the $\mathrm{GH} 11$ basal cutting was treated with 2000 ppm IBA. The results indicated that the production of clones with survival rates of less than $20 \%$ should be discarded since it makes no economic sense clones with survival rates of more than $40 \%$ should be planted out in the field to compare field performance with greenhouse survival.

\section{Background}

Originally from Australia, Eucalyptus is a fast growing tree specie which accounts for 17.8 million hectares(ha) of planted forests globally and is also used worldwide for pulp and paper, timber and fuel wood (Tournier et al., 2003). World population growth has placed tremendous pressure on forestry and agriculture, due to the fact that these growing populations need to be fed, clothed and housed (Diner, 1999). Natural regeneration of Eucalyptus species mainly occurs through seed germination. This means 
plants would need at least two years to mature enough to produce seeds before propagation of these plants can take place which requires the luxury of more time which may not be feasible considering economical and demand factors. Naturally, most Eucalypts begin to produce seeds two years after planting. Traditionally, collection of seeds in bulk from randomly pollinated superior trees is the method for propagating forest trees and these seeds have been found to be susceptible to genetic damage and rapid loss of variability over time (Ahuja, 1993). Most of the planting stock is still produced from seeds of unselected genotypes (Husen and Pal, 2006). This usually leads to poor stand establishment in forest plantations.

While cloning of Eucalyptus species in the last two decades has produced substantial progress for forest companies, the focus of cloning has also shifted to industrial requirements, rather than remaining limited to disease resistance and volume increase (Sivarajan et al., 2014). Vegetative propagation has been used in forestry to produce many elite individuals obtained in breeding programmes and adventitious rooting which is an essential step in this method of propagation is a complex process affected by multiple factors (Schwambach et al., 2005). The use of clonal cuttings to multiply population of forest trees is a promising practice that has been ongoing for decades, this journey has however not been devoid of shortcomings such as poor rooting and plant death. Researchers have sought to find out the best methods of successfully producing clones of trees usually from stock banks. Vegetative propagation of Eucalyptus genera is carried out to greater degrees of sophistication in most forestry companies that have adopted clonal propagation to improve yield and quality (Sulichantini et al., 2014). However in Ghana, clones that have been found to combine fast growth and tolerance to pests and diseases as are the $E$. grandis $x$ E. urophylla and $E$. pellita species. However the ability of these species to root effectively is poor and has to be enhanced with Indole-3-butyric acid (IBA). Despite the large number of Eucalyptus species existing worldwide, less than twenty are actively used for commercial plantations (Almeida et al., 2010). According to (Rezende et al., 2017), the tropical interspecific hybrid type between Eucalyptus grandis and Eucalyptus urophylla popularly known as Eucalyptus "urograndis" has over the years been established as the world-class benchmark for clonal productivity because it combines fast growth, excellent rooting ability, tolerance to pests and diseases as well as wood quality suitability for a broad range of uses. Research evidence suggests that auxins play a central role in the determination of rooting capacity, by enabling the faster production of rooted cutting material which is essential for vegetative propagation (Fogaça and Fett-Neto, 2005).

Exogenous auxins are vital in the determination of rooting capacity, whereas most commercial propagation is done by rooting with IBA (Kotis et al., 2009). Global mean productivity of Eucalyptus clonal plantations has in the last 30 years increased from $25-30 \mathrm{~m}^{3} / \mathrm{ha}$ /year to $35-45 \mathrm{~m}^{3} / \mathrm{ha} /$ year with exceptional cases where productivity exceeds $60 \mathrm{~m}^{3} /$ ha/year (Rezende et al., 2017). Eucalyptus species have a wide range of uses that mainly depend on the intentions of tree growers. In South Africa, Eucalyptus is grown to provide wood chip to Japan for paper manufacture as well as for firewood, construction, timber and charcoal whereas it is used in Uganda to support climbing beans with as many as 50,000 stakes per hectare (Kilimo Trust, 2011). 
This study focused on establishing ways by which successful rooting of Eucalyptus grandis $\times$ Eucalyptus urophylla and Eucalyptus pellita cuttings can be achieved using four concentrations of IBA applied exogenously.

\section{Materials And Methods}

This experiment was carried out at the plant nursery site of Miro Forestry Company Limited which is located in Agogo in the Asante-Akim North Municipal District of the Ashanti Region of Ghana. The plantation area is located about $7^{\circ}$ north of the equator and has a tropical climate with average monthly temperatures ranging between $24^{\circ} \mathrm{C}$ and $28^{\circ} \mathrm{C}$ and annual rainfall between $1,300 \mathrm{~mm}-1,650 \mathrm{~mm}$.

\subsection{Materials}

A pair of mini shears was used to excise the cuttings from the parent plant (ortet). The cuttings were then placed immediately in a bucket of water and thereafter trimmed with a pair of scissors. $99 \%$ concentrated Indole-3-Butyric Acid (IBA) and talcum powder both purchased from Dizengoff Ghana Limited were mixed in specific ratios with the aid of a weighing balance to give the desired hormone concentrations in parts per million (ppm).

\subsection{Methods}

Ten clones each of Eucalyptus grandis $\times$ Eucalyptus urophylla and Eucalyptus pellita were used in this research. IBA concentrations of 0 ppm (control), 2000 ppm, 3000pmm and 4000 ppm were applied to apical cuttings of the two tree species used in this research. Indole-3-Butyric Acid (IBA) was the only rooting hormone used in this research. In preparing the different concentrations of IBA, the weighing balance was first calibrated with a known weight of $50 \mathrm{~g}$ which was made of steel. Both concentrated IBA powder and talcum powder were gently weighed on the balance with respect to each of the concentrations used in this research. Measured amounts of IBA and talcum powder for each respective hormone were thoroughly mixed. For 0 ppm cuttings were just planted in the trays after trimming. Mixtures were done as follows to obtain desired hormone concentrations for the research:

- $0.2 \mathrm{~g}$ of IBA into $10 \mathrm{~g}$ of talcum powder $=2000 \mathrm{ppm}$ of rooting hormone.

- $0.3 \mathrm{~g}$ of IBA into $10 \mathrm{~g}$ of talcum powder $=3000 \mathrm{ppm}$ of rooting hormone.

- $0.4 \mathrm{~g}$ of IBA into $10 \mathrm{~g}$ of talcum powder $=4000 \mathrm{ppm}$ of rooting hormone.

The basal tip of the cutting where excision was made was dipped into the prepared hormone powder with respect to the different concentrations used, after which the cutting was planted in the cocopeat (planting medium) filled trays.

Eucalyptus pellita had a code name beginning with the letter ' $\mathrm{P}$ ' and ending with a number ( $\mathrm{P} 1, \mathrm{P} 2, \mathrm{P} 11$, P15, P46, P56, P82, P83, P95 and P98) while Eucalyptus grandis $\times$ Eucalyptus urophylla clones had their code names beginning with ' $\mathrm{GH}$ ' and ending with a number ( $\mathrm{GH} 3, \mathrm{GH} 7, \mathrm{GH} 10, \mathrm{GH} 11, \mathrm{GH} 14, \mathrm{GH} 19, \mathrm{GH} 27$, 
$\mathrm{GH} 29, \mathrm{GH} 31$ and GH32). In this study twenty-four cuttings each of the clones were treated with the above mentioned concentrations of rooting hormones with four replications each making a total of 112 cuttings per experiment. Cuttings which had visible roots and were green and healthy 28 days after planting (DAP) were said to have survived.

Cuttings were collected from a two year old clonal hedge stand. Two to three week old sprouts were collected and trimmed to single-stemmed apical and basal cuttings respectively and before treatment with a determined concentration of IBA. Cuttings were immersed in water immediately after excision from ortets to reduce environmental shocks on the plant.

\subsection{Statistical analyses}

Survival results of the clones were subjected to Analysis of variance (ANOVA) tests to find out if differences between survivals with respect to levels of IBA concentrations were significant. Results were also further subjected to Tukey's Test of Multiple Comparisons to find out the exact treatments at which significant differences occurred.

\section{Results}

Eucalyptus grandis $\times$ Eucalyptus urophylla cutting survival with respect to hormone concentration.

Cuttings which had visible roots and were green and healthy 28 DAP planting were said to have survived. Mean survival of cuttings from all $10 \mathrm{GH}$ clones were low (i.e $<50 \%$ ) for all concentrations of IBA used in this research. Survival rates of individual clones however varied from clone to clone as shown in Figs. 2.1 and 2.2 respectively. GH7 cuttings achieved highest survival (68.75\%) when treated with $2000 \mathrm{ppm}$ of IBA and lowest survival (41.96\%) when treated with 4000 ppm of IBA.

For all $10 \mathrm{GH}$ clones, the lowest survival (7.14\%) was recorded when $\mathrm{GH} 31$ cuttings were treated with 0 ppm (IBA). GH 3, GH 10 and GH32 also recorded their highest survivals (i.e $66.07 \%, 61.61 \%$ and $31.25 \%$ ) respectively when treated with $0 \mathrm{ppm}$ Clones $\mathrm{GH} 29$ and $\mathrm{GH} 32$ achieved survival rates of less than $40 \%$ for all levels of IBA concentrations used.

Eucalyptus pellita cutting survival with respect to hormone concentration.

In this study, E. pellita cutting survival was also assessed with respect to varying hormone concentrations used in this research. Figures 2.3 and 2.4 display results of survival rates in terms of percentages for each of the 10 clones of E. pellita used in this research. From Fig. 2.3 clone P2 achieved the highest survival (52.68\%) when treated with 0 ppm of IBA (control experiment) and lowest survival $(37.50 \%)$ was also recorded when clone treated with 3000 ppm of IBA.

The lowest survival (1.79\%) for all 10 E. pellita $(\mathrm{P})$ was recorded when P82 was treated with $0 \mathrm{ppm}$ IBA. Mean survival as displayed for all concentrations of IBA used in this research was low (i.e $<50 \%$ ). Clones P11, P51 and P82 recorded survival rates less $20 \%$ for all concentrations of IBA used. 
Table 2.1: Summary of Tukey's test conducted for GH-IBA concentration interaction.

\begin{tabular}{|llll|}
\hline Tukey's multiple comparisons test & Mean Diff. & Adjusted P Value \\
\hline GH27:2000 ppm vs. GH27:4000 ppm & 13.5 & $0.0003^{*}$ \\
\hline GH27:2000 ppm vs. GH27:Controlppm & 12.5 & $0.0015^{\star}$ \\
\hline GH31:2000 ppm vs. GH31:4000 ppm & 10.25 & $0.0393^{\star}$ \\
\hline GH31:2000 ppm vs. GH31:Controlppm & 11 & $0.0144^{\star}$ \\
\hline *= significant difference between interaction & \\
\hline
\end{tabular}

Table 2.1 displays some significant differences as indicated by the Tukey's test of multiple comparisons between clones with respect to cutting-I.BA interactions. Some individual clones such as GH27 and GH31 exhibited significant differences with respect to the interaction being tested for. Tukey's test results as shown indicates the corresponding adjusted P values between clones GH27 and GH31.

\section{Discussion}

Four out of the ten E. grandis $\times$ E. urophylla clones used in this research (i.e GH7, GH14, GH27, GH31) had the highest survival rates when treated with 2000 ppm of IBA. Survival results for Eucalyptus pellita cuttings did not vary from the trend of E. grandis $\times E$. urophylla as survival rates continued to vary with respect to alterations in IBA concentration. This is in agreement with (Carter and Slee, 1993; Maile and Nieuwenhuis, 1996) reports that; the propagation of cuttings is dependent on the concentrations and application methods of exogenous rooting hormones. Overall mean survival rate was computed based on each of the concentrations of IBA used and $2000 \mathrm{ppm}$ of IBA yielded the highest survival rate (i.e 43.39\%) followed by the control (37.86\%), $3000 \mathrm{ppm}(36.52 \%)$ and then lastly $4000 \mathrm{ppm}(31.70 \%)$ which goes agrees with findings by (Kotis et al., 2009) that exogenous auxins are vital for rooting capacity as well as survival of cuttings.

Clone GH3 treated with I.BA concentrations 2000 ppm, 3000 ppm, 4000 ppm and 0 ppm, had survival rates of $45.54 \%, 47.32 \%, 45.54 \%$ and $66.07 \%$ respectively.

Clone P1 survival rates recorded were $36.61 \%, 50 \%, 41.07 \%$, and $36.61 \%$ for concentrations of 2000 ppm, 3000 ppm, 4000 ppm and 0 ppm respectively. Clone P82 recorded very low survival rates for all four hormone concentrations used. Survival rates for P82 were $5.36 \%, 5.36 \%, 2.68 \%$ and $1.79 \%$ for $2000 \mathrm{ppm}$, 3000 ppm, 4000 ppm and 0 ppm respectively. Overall survival rates for clone P51 was also low (i.e $<10 \%$ ) for all hormone concentrations used which shows that individual clones of the same species respond differently to IBA treatments and this could be as a result of genetic, provenance and other environmental factors.

ANOVA analysis conducted on survival results showed that variations between $E$. grandis $\times E$. Urophylla cuttings were significant. These significant differences occurred within specific clones in relation to IBA 
concentration whereas Tukey's test of multiple comparisons identified specific interactions that gave these significant differences. This suggests that although survival may be influenced by hormone concentration in some clonal species, survival also is dependent on the type of clone which is being treated with different concentrations of IBA. Rooting is maximized when the optimal combinations of factors is achieved (Dick and Dewar, 1992). Clone GH27 exhibited significant variations when treated with different concentrations of rooting hormone while $\mathrm{GH} 3$ and $\mathrm{GH} 11$ exhibited no significant differences.

\section{Conclusion And Recommendation}

This study was conducted to find out the survival rates of Eucalyptus pellita and Eucalyptus grandis $\times$ E. urophylla cuttings in response to IBA concentrations of 0 ppm, 2000 ppm, 3000 ppm and 4000 ppm. Overall, both species exhibited highest mean survival rates when 2000 ppm of I.BA was applied. The mean survival rate of E. grandis $\times$ E. Urophylla was $43.39 \%$ while that of Eucalyptus pellita was relatively low at $27.14 \%$. These mean calculations were based on ten clones of the two species used. Some individual clones survived best when no IBA was applied (i.e GH10-61.61\%, GH32-31.25\%, and P2$52.68 \%$ ) and this sets a precedent for processing specific clonal cuttings without the exogenous rooting hormone application by Miro Forestry Limited.

Further studies should be conducted to assess the performance of $E$. grandis $\times E$. urophylla and Eucalyptus pellita clones with respect to cutting type and hormone concentration and also go on field trials in order to compare in-greenhouse survival rates to on-field survival rates. With regards to findings from this research, the assessment of the effect of the genetic compositions of individual clones on overall cutting success will be examined in the near future.

\section{Declarations}

- Ethics approval and consent to participate

Not applicable

- Consent for publication

Not applicable

- Availability of data and material

The datasets generated and/or analyzed during the current study are available from the corresponding author on reasonable request

- Competing interests

The authors declare that they have no competing interests 
- Funding

Not applicable

- Authors' contributions

NYS carried out the research over the period, recorded and analyzed data. FOA, my Mphil co-supervisor proofread the compiled documents and made corrections. DEKAS; my main supervisor laid out the research and analysis methods for this research as well as constantly proofreading and making additions and deduction.ME; supervised the field research work.

\section{ACKNOWLEDGEMENTS}

The authors would like to thank all the staff and management of Miro Forestry Limited, especially the Nursery and Research and Development departments for allowing us to use their equipment in carrying out this research.

\section{References}

1. Ahuja, M.R. 1993. Biotechnology and clonal forestry. In: Ahuja, M.R. and Libby, W.J. (eds). Clonal Forestry I: Genetics and Biotechnology. Springer-Verlag. Berlin, Heidelberg. pp 135 - 144.

2. Almeida, A.C., Siggins, A., Batista, T.R., Beadle, C., Fonseca, S., Loos, R., 2010. Mapping the effect of spatial and temporal variation in climate and soils on Eucalyptus plantation production with 3-PG, a process-based growth model. For. Ecol. Manage. 259, 1730-

3. Carter, A.S. and Slee, M.U. 1993. Is IBA an effective promoter of root formation on cuttings of Eucalyptus grandis? Proceedings of the International Plant Propagators' Society 43: $109-113$.

4. Dick JMcP and Dewar RC (1992) A mechanistic model of carbohydrate dynamics during adventitious root development in leafy cuttings. Annals of Botany 70: 371- 377.

5. Diner Alex. 1999. Somatic embryogenesis in forestry: A practical approach to cloning the best In: Wheeler, Robert, Under the canopy; forestry and forest products newsletter of the Alaska Cooperative Extension. Fairbanks, AK: University of Alaska Fairbanks Cooperative Extension Service: 7-8.

6. Fogaca C. M., Arthur G. Fett-Neto (2005), Role of auxin and its modulators in the adventitious rooting of Eucalyptus species differing in recalcitrance, Plant Growth Regulation (2005) 45: 1-10.

7. Husen Azamal, Mohinder Pal. (2006) 'Variation in shoot anatomy and rooting behaviour of stem cuttings in relation to age of donor plants in teak (Tectona grandis Linn. f.)', Plant Physiology, Botany Division, Forest Research Institute, P.O. New Forest, Dehra-Dun 248006, New Forests (2006) 31:57-73.

8. Kilimo Trust 2011. Eucalyptus Hybrid Clones in East Africa; Meeting the Demand for Wood through Clonal Forestry Technology. Occassional Paper No.1. 
9. Kotis, M., T.A. Yupsanis, T.D. Syros and A.S. Economou. 2009. Peroxidase, acid phosphatase, 'RNase and DNase activity and isoform patterns during in vitro rooting of Petuniaxhybrida microshoots. Biologia Plantarum, 53(3): 530-538.

10. Maile, N. and Nieuwenhuis, M. 1996. Vegetative propagation of Eucalyptus nitens using stem South African Forestry Journal 175: 29 - 34.

11. Schwambach, J., Fadanelli, C., Fett-neto, A. G., (2005) 'Mineral nutrition and adventitious rooting in microcuttings of Eucalyptus globulus', Heron Publishing-Victoria, Canada, ' 25: 487-494.

12. Sivarajan, A., M. Anbazhagan, K. Arumugam, (2014) 'Clonal propagation of Eucalyptus grandis using different techniques', Universal Research Publications, International Journal of Research in Plant Science 2014; 4(2): 42-45.

13. Sulichantini, E.D., Sutisna, M., Sukartiningsih, Rusdiansyah. 2014. Clonal Propagation of Two Clones Eucalyptus Pellita F. Muel/ By Mini-Cutting , International Journal of Science and Engineering, 6(2), 112-116.

14. Rezende, G. D. S. P., Marcos Deon V. de Resende, Teotônio F. de Assis,2017.Eucalyptus Breeding for Clonal Forestry, T. Fenning (ed.), Challenges and Opportunities for the World's Forests in the 21 st Century, Forestry Sciences 81.

15. Tournier,V., Sabine Grat, Christiane Marque, Walid El Kayal1, Ricardo Penchel, Gisele de Andrade, Alain-Michel Boudet, Chantal Teulières (2003) 'An efficient procedure to stably introduce genes into an economically important pulp tree (Eucalyptus grandis $\times$ Eucalyptus urophylla)', Kluwer Academic Publishers, 12: 403-411.

\section{Figures}

GH CLONE SURVIVAL WITH RESPECT TO IBA CONCENTRATION.

$\square 2000 \mathrm{ppm} \quad \square 3000 \mathrm{ppm} \quad \square 4000 \mathrm{ppm} \quad \mathbf{\square} \operatorname{control}(0 \mathrm{ppm})$

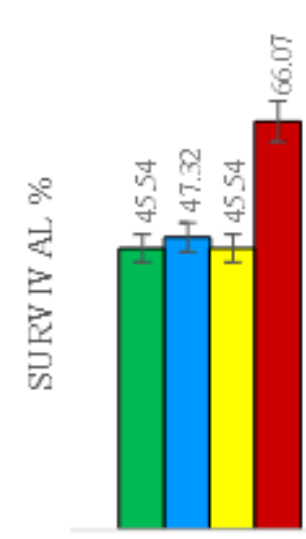

GH3

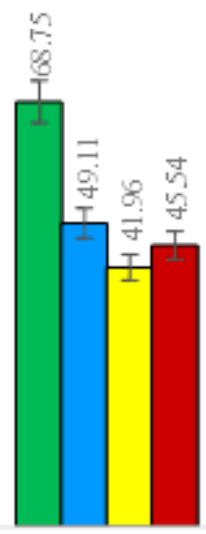

GH 7

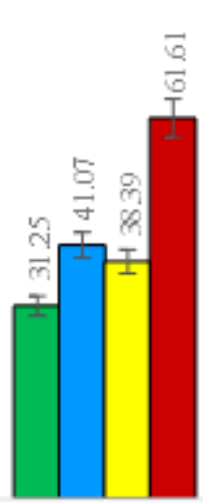

GH 10

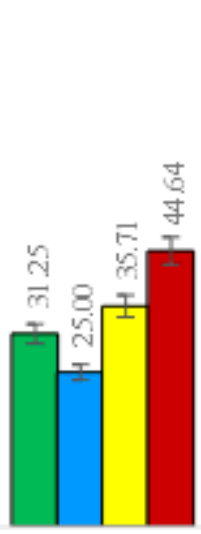

GH1 1

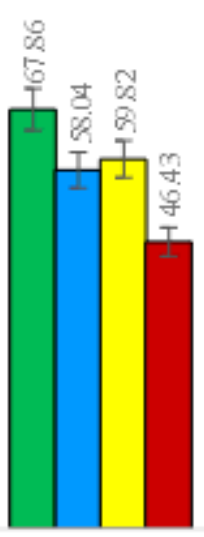

GH 14

CLONE IDENTITY 
Figure 1

GH Clone survival with respect to four levels of IBA.

GH CLONE SURVIVAL WITH RESPECT TO IBA CONCENTRATION.

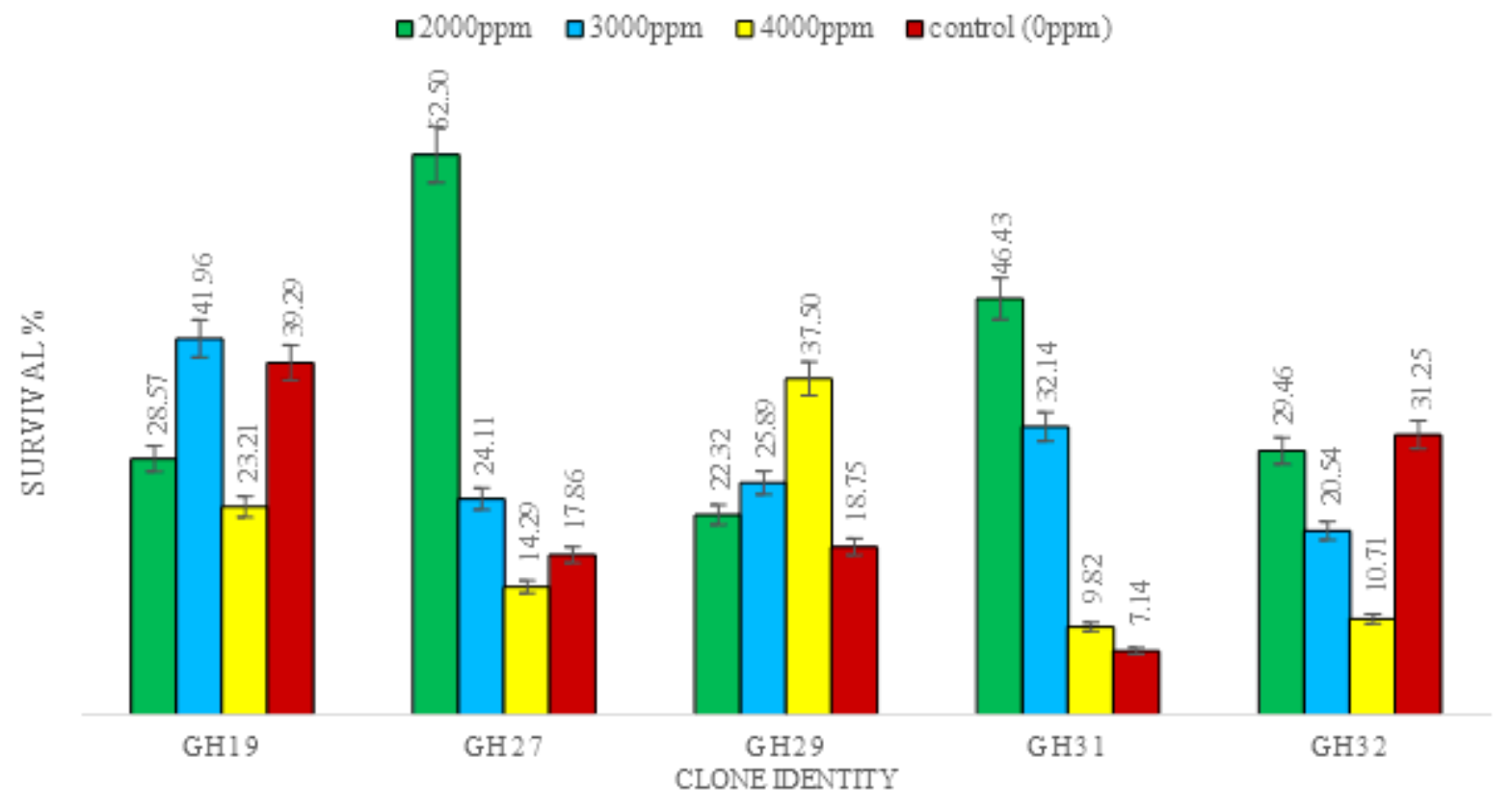

Figure 2

GH Clone survival with respect to four levels of IBA.

E. pellita SURVIVAL WITH RESPECT TO IBA

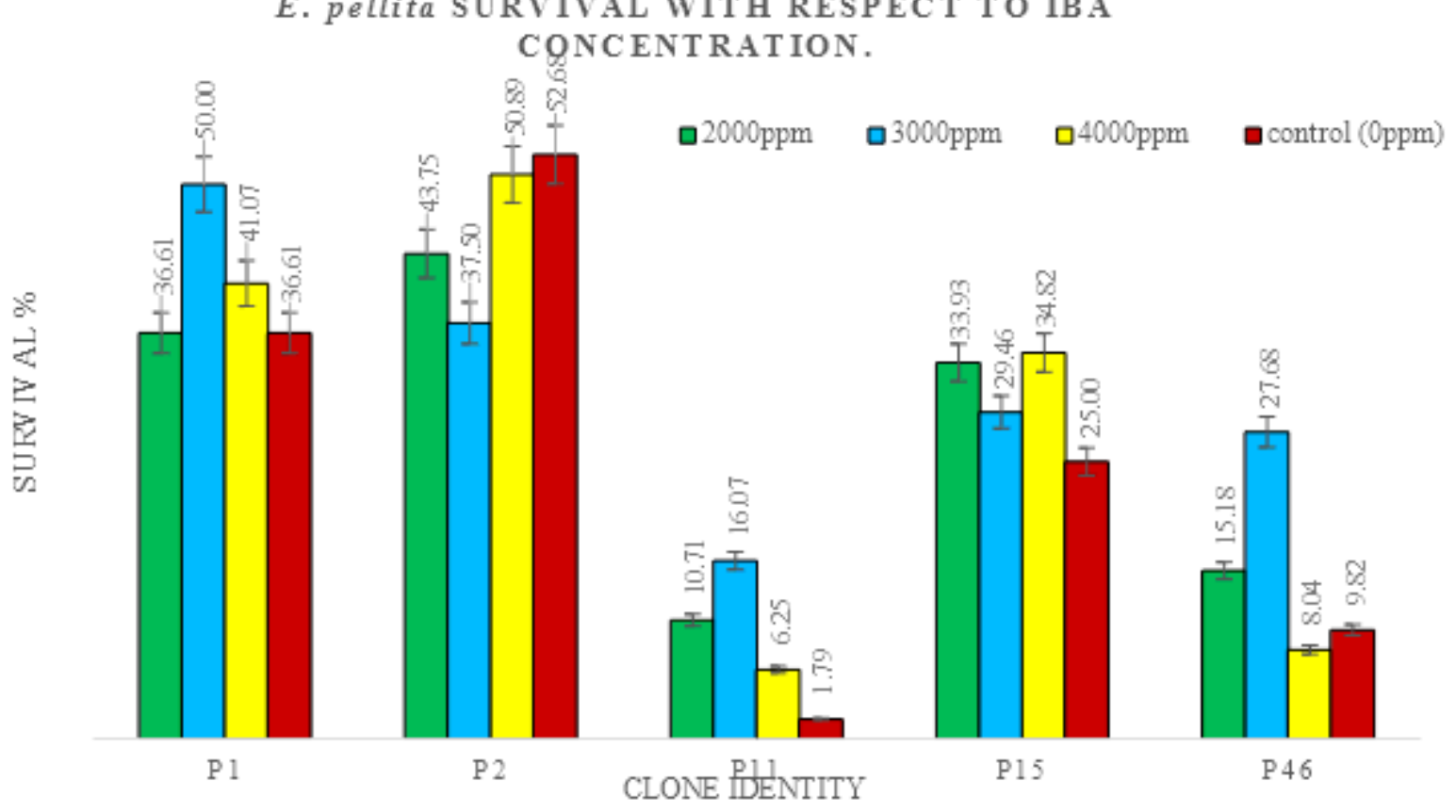

Figure 3

E. pellita (P) Clone survival with respect to four levels of IBA. 
E. pellita SURVIVAL WITH RESPECT TO IBA CONCENTRATION

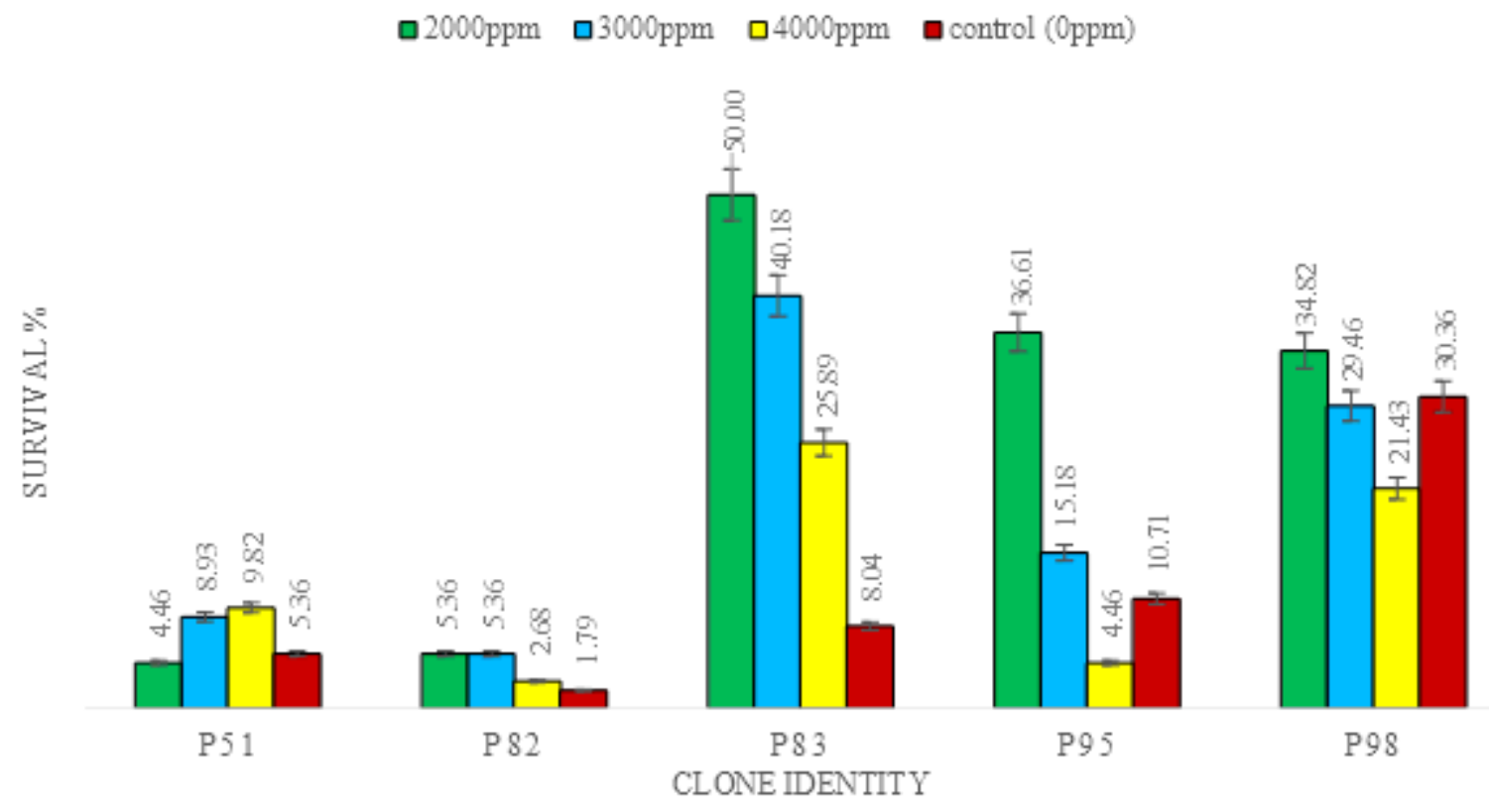

Figure 4

E. pellita $(P)$ Clone survival with respect to four levels of IBA concentration.

\section{Supplementary Files}

This is a list of supplementary files associated with this preprint. Click to download.

- NanaYawSarponglBAandcuttingsurvivalpaper.pdf 